Article

\title{
Impact of Hydrolyzed Collagen from Defatted Sea Bass Skin on Proliferation and Differentiation of Preosteoblast MC3T3-E1 Cells
}

\author{
Lalita Chotphruethipong ${ }^{1}$, Thunwa Binlateh ${ }^{2}$, Pilaiwanwadee Hutamekalin ${ }^{3} \mathbb{D}$, Rotimi E. Aluko ${ }^{4, * \mathbb{D}}$, \\ Surapun Tepaamorndech ${ }^{5}$, Bin Zhang ${ }^{6}$ and Soottawat Benjakul ${ }^{1, *(D)}$
}

1 International Center of Excellence in Seafood Science and Innovation, Faculty of Agro-Industry, Prince of Songkla University, Hat Yai, Songkhla 90110, Thailand; lalitac.ch@psu.ac.th

2 School of Geriatric Oral Health, Institute of Dentistry, Suranaree University of Technology, Nakhon Ratchasima 30000, Thailand; thunwa.bin@gmail.com

3 Division of Health and Applied Sciences, Faculty of Science, Prince of Songkla University, Hat Yai, Songkhla 90110, Thailand; pilaiwanwadee.h@psu.ac.th

4 Department of Food and Human Nutritional Sciences, University of Manitoba, Winnipeg, MB R3T 2N2, Canada

5 National Center of Genetic Engineering and Biotechnology Center (BIOTEC), National Science and Technology Development Agency (NSTDA), 113 Thailand Science Park, Pathumthani 12120, Thailand; surapun.tep@biotec.or.th

6 College of Food and Pharmacy, Zhejiang Ocean University, Zhoushan 316022, China; zhanbin@zjou.edu.cn

* Correspondence: rotimi.aluko@umanitoba.ca (R.E.A.); soottawat.b@psu.ac.th (S.B.); Tel.: +66-7428-6334 (S.B.)

check for updates

Citation: Chotphruethipong, L.; Binlateh, T.; Hutamekalin, P.; Aluko, R.E.; Tepaamorndech, S.; Zhang, B.; Benjakul, S. Impact of Hydrolyzed Collagen from Defatted Sea Bass Skin on Proliferation and Differentiation of Preosteoblast MC3T3-E1 Cells. Foods 2021, 10, 1476. https://doi.org/ $10.3390 /$ foods 10071476

Academic Editor: Maria Hayes

Received: 22 May 2021

Accepted: 18 June 2021

Published: 25 June 2021

Publisher's Note: MDPI stays neutral with regard to jurisdictional claims in published maps and institutional affiliations.

Copyright: (c) 2021 by the authors. Licensee MDPI, Basel, Switzerland. This article is an open access article distributed under the terms and conditions of the Creative Commons Attribution (CC BY) license (https:// creativecommons.org/licenses/by/ $4.0 /)$.

\begin{abstract}
Osteoporosis is a serious problem affecting health of the elderly. Drugs (bisphosphonates) applied for treatment are often accompanied by adverse side effects. Thus, fish byproduct-derived peptides, particularly hydrolyzed collagen (HC) from defatted sea bass skin, could be a safe source of anti-osteoporosis agents. This study aimed to examine the effects of $\mathrm{HC}$ on proliferation and differentiation of preosteoblast cells. HC prepared using papain before Alcalase hydrolysis was determined for molecular weight (MW) distribution. Thereafter, the resulting HC $(50-800 \mu \mathrm{g} / \mathrm{mL})$ was added to the cell. Proliferation, alkaline phosphatase activity (AP-A) and mineralization of cells were investigated. Moreover, the expression of runt-related transcription factor 2 (RUNX2) and the p-Akt/Akt pathway were also determined using Western blot. The results showed that $\mathrm{HC}$ had an MW < $3 \mathrm{kDa}$. HC (50-200 $\mu \mathrm{g} / \mathrm{mL})$ could promote cell proliferation. Nevertheless, HC at $100 \mu \mathrm{g} / \mathrm{mL}$ (HC-100) had enhanced AP-A and increased mineralization during the first 7 days of culture. Moreover, HC-treated cells had higher calcium depositions than the control $(p<0.05)$. Additionally, cells treated with HC-100 had higher levels of RUNX2 and p-Akt expressions than control $(p<0.05)$. Therefore, HC could be a promising functional ingredient to promote osteoblast proliferation and differentiation, which could enhance bone strength.
\end{abstract}

Keywords: bioactive peptides; sea bass; osteoblast; differentiation; hydrolyzed collagen; bone

\section{Introduction}

Osteoporosis is a severe problem found in the elderly, which is mainly associated with bone fragility [1]. Lack of estrogen or nutrients, aging and chronic diseases are the main causes of osteoporosis [2]. Recently, bisphosphonates have been used to prevent or treat osteoporosis $[3,4]$, but their uses are accompanied by negative side effects, especially the risk for gastrointestinal toxicity [5].

To avoid this limitation, the natural compounds with high biological activity and safety such as hydrolyzed collagen (HC) from fish processing byproducts could be applied to alleviate osteoporosis owing to their biocompatibility, profound activity and rapid in vivo clearance [6,7]. Additionally, fish HC could be utilized in many foods without 
the limitation or unacceptability due to cultural and religious restrictions [8]. In general, collagen is the main constituent of bone extracellular matrix [9]. Collagen serves as a template and may also initiate and propagate mineralization independent of the matrix vesicles, resulting in bone toughness and bone strength [10]. Fish HC has been proven to possess the ability to promote bone formation. Yamada et al. [11] revealed that fish collagen peptides could increase collagen synthesis and mineralization of osteoblastic MC3T3-E1 cells. Moreover, hydroxyproline content, alkaline phosphatase level and mineral density of aged mice were enhanced after ingestion of HC from silver carp skin [7]. Thus, fish $\mathrm{HC}$ is promising for inducing differentiation of osteogenic cells, leading to augmented bone formation.

HC from defatted sea bass skin is one of the excellent sources of peptides rich in various bioactivities, including fibroblast proliferation, antioxidant and wound-healing activities [12,13]. Moreover, the sea bass skin contains peptides with Pro-Hyp or X-HypGly [14], which could promote differentiation of MC3T3-E1 cells [15]. Nevertheless, effects of HC from defatted sea bass skin on the proliferation and differentiation of MC3T3-E1 pre-osteoblast cells have not been reported. Thus, the purpose of the present study was to examine the cell proliferation and differentiation property of the HC from defatted sea bass skin with emphasis on calcium deposition and protein expression.

\section{Materials and Methods}

\subsection{Chemicals}

Alcalase and papain were purchased from Siam Victory Chemicals Co, Ltd. (Bangkok, Thailand). Porcine pancreas lipase (PPL), BCIP/NBT and other chemicals were supplied by Sigma-Aldrich Chemical Co. (St. Louis, MO, USA). Antibiotics, fetal bovine serum (FBS) and modified $\alpha$-Minimum Essential Medium Eagle ( $\alpha$-MEM) without ascorbic acid were obtained from Gibco ${ }^{\circledR}$, Thermo Fisher Scientific Inc. (Waltham, MA, USA). MC3T3E1 subclone 4 was procured from ATCC (Bethesda, MD, USA). RUNX2 and Akt, p-Akt (s473) were obtained from Abcam, Cambridge, UK, and Cell Signaling (Danvers, MA, USA), respectively.

\subsection{Enzyme Assays}

PPL activity was measured following the protocol of Chotphruethipong et al. [1]. One unit of activity was defined as the amount of PPL that produces $1 \mu \mathrm{mol} p$-nitrophenol $(p-\mathrm{NP}) / \mathrm{min}$. Activities of papain $\left(\mathrm{pH} \mathrm{7.0,} 40{ }^{\circ} \mathrm{C}\right)$ and Alcalase $\left(\mathrm{pH} 8.0,50{ }^{\circ} \mathrm{C}\right)$ were assayed for $15 \mathrm{~min}$ using casein as substrate. One unit of activity was defined as the amount of papain or Alcalase that liberates $0.01 \mu \mathrm{mol}$ of tyrosine equivalent $/ \mathrm{min}(\mu \mathrm{mol}$ Tyr equivalent/min).

\subsection{Preparation and Pretreatment of Sea Bass Skin Using Pulsed Electric Field (PEF)}

The skins $\left(2 \times 2 \mathrm{~cm}^{2}\right)$ were first treated with $0.1 \mathrm{M} \mathrm{NaOH}$ and subsequently washed with tap water [1] prior to PEF pretreatment [2]. Electric field intensity at $24 \mathrm{kV} / \mathrm{cm}$ with $72 \mathrm{~ms}$ pulses was used. Pulse duration, specific energy input and pulse repetition times were $0.1 \mathrm{~ms}, 135 \mathrm{~kJ} / \mathrm{kg}$ and $20 \mathrm{~ms}$, respectively. When PEF treatment was completed, the skins were swollen using $0.05 \mathrm{M}$ citric acid for $2 \mathrm{~h}$, followed by washing until a neutral $\mathrm{pH}$ was reached [2].

\subsection{Defatting of PEF-Treated Skin}

Swollen skins ( $200 \mathrm{~g}$ ) were mixed with $1 \mathrm{~L}$ of PPL solution containing $42.36 \mathrm{U} / \mathrm{g}$ dry matter in a vacuum chamber [3]. The vacuum impregnation process was performed for 4 cycles under $100 \mathrm{kPa}$ pressure [3]. The defatted swollen skin was further used for preparing hydrolyzed collagen $(\mathrm{HC})$. 


\subsection{HC Preparation}

A 2-step hydrolysis was used for producing the HC. Firstly, the defatted swollen skin was treated with papain $\left(0.3 \mathrm{U} / \mathrm{g}\right.$ dry matter) at $40{ }^{\circ} \mathrm{C}$ for $90 \mathrm{~min}$. Heating at $90{ }^{\circ} \mathrm{C}$ for 15 min was subsequently applied to inactivate papain. The obtained hydrolysate was further hydrolyzed using Alcalase $\left(0.3 \mathrm{U} / \mathrm{g}\right.$ dry matter) at $50{ }^{\circ} \mathrm{C}$ for $90 \mathrm{~min}$, followed by inactivation of enzyme via heating $\left(90^{\circ} \mathrm{C}, 15 \mathrm{~min}\right)$. The resulting digest was filtered and lyophilized as the HC powder following the procedure of Chotphruethipong, Aluko and Benjakul [1].

\subsection{Size Distribution}

Molecular weight of HC was determined by MALDI-TOF-MS, as detailed by Benjakul et al. [4].

\subsection{Impact of HC on Proliferation and Differentiation of MC3T3-E1 Preosteoblast Cells \\ 2.7.1. Cell Culture}

MC3T3-E1 cells were cultured in complete $\alpha$-MEM medium containing 10\% FBS and antibiotics, as described by Paisrisarn et al. [5].

\subsubsection{Cell Proliferation Assays}

HC was dissolved in $\alpha$-MEM medium containing $10 \%$ or $1 \%$ FBS to obtain different concentrations (50,100, 200, 400 and $800 \mu \mathrm{g} / \mathrm{mL})$. HC at all concentrations was tested for cell proliferation using 3-(4, 5-dimethylthiazol-2-yl)-2, 5-diphenyl tetrazolium bromide (MTT) assay [16]. Moreover, cell morphology after treatment with HC was visualized using a microscope (Olympus IX70 with DP50, Shinjuku-ku, Tokyo, Japan). The levels rendering the highest cell proliferation were selected for measurement of alkaline phosphatase activity and mineralization studies.

Before testing, MC3T3-E1 cells $\left(5 \times 10^{3}\right.$ cells/well) were seeded in a 24-well culture plate using the differentiation medium (DM) containing $10 \% \mathrm{FBS}, 50 \mu \mathrm{g} / \mathrm{mL}$ ascorbic acid, $1 \mu \mathrm{M}$ dexamethasone and $10 \mu \mathrm{M} \beta$-glycerophosphate followed by incubation for $12 \mathrm{~h}$. Thereafter, the medium was removed and cells were washed with $1 \mathrm{~mL}$ of sterile phosphate buffer (SPB). DM with $\mathrm{HC}$ at the selected concentrations was added into cells and cultured for 7, 14 and 21 days. The medium was changed every 2-3 days. At the designated days, cells were analyzed for alkaline phosphatase activity and mineralization.

\subsubsection{Alkaline Phosphatase Activity (AP-A)}

The $p$-nitrophenyl phosphate ( $p$-NPP) assay was used for measuring AP-A in cells [6]. The optical density was detected at a wavelength of $405 \mathrm{~nm}$ using a microplate reader (FLUOstar Omega, BMG Labtech Multi-mode microplate reader, Offenburg, Germany). AP-A was reported as micromolar $(\mu \mathrm{M})$ using a standard curve according to the manufacturer's instructions.

For staining, the levels of AP-A were also assessed using BCIP/NBT alkaline phosphatase liquid substrate. The cells were incubated with BCIP/NBT solution for $1 \mathrm{~h}$ in the dark. After staining, the cells were visualized for AP-A levels using a microscope. The blue intensity was analyzed using Image 1.41 software (NIH, Bethesda, MD, USA) and presented as relative intensity to that of control cells.

\subsubsection{Determination of Mineralization in MC3T3-E1 Cells}

After incubation with $\mathrm{HC}$ at the designated time, the cells were washed gently with SPB and fixed with $4 \%$ paraformaldehyde for $30 \mathrm{~min}$. After fixing, the cells were stained with $1 \%$ alizarin red dye for $1 \mathrm{~h}$ at room temperature. Thereafter, the stained cells were washed with SPB and visualized using a microscope. Calcium deposition of cells indicated by alizarin red staining was examined using ImageJ software and was reported as a relative calcium deposition to that of control. Apart from analysis using ImageJ software, mineralization of cells was measured using absorbance at $405 \mathrm{~nm}$. Alizarin red-stained cells were 
rinsed with $10 \%$ cetylpyridinium chloride and incubated for $1 \mathrm{~h}$ at room temperature. The resulting color of red mineralized nodules was measured using an absorbance at $405 \mathrm{~nm}$.

Cells treated with $\mathrm{HC}$ at concentration and incubation time that produced the highest AP-A and mineralization in cells were used for Western blot analysis. Cells without HC treatment at the same incubation time were also analyzed.

\subsubsection{Western Blot Analysis}

After treatment with the selected conditions, cells $\left(1 \times 10^{6}\right.$ cells $/ 35-\mathrm{mm}$ dish $)$ were lysed with RIPA buffer containing freshly added protease inhibitor cocktail. The obtained lysates were centrifuged at $32,869 \times g$ (Beckman Coulter, Inc., Palo Alto, CA, USA) for $15 \mathrm{~min}$ at $4{ }^{\circ} \mathrm{C}$. The supernatants were collected and measured for total protein concentration using the Bradford method (Bio-Rad Laboratories, Hercules, CA, USA). The proteins $(30 \mu \mathrm{g})$ were equally subjected to SDS-PAGE and transferred onto PVDF membranes. Nonspecific bindings were blocked with 5\% skimmed milk or 3\% BSA. The membranes were then incubated with primary antibodies against Akt, p-Akt (s473) and RUNX2, followed by incubation with HRP-conjugated secondary antibody for $1.5 \mathrm{~h}$. The proteins of interest were detected using Super Signal West Pico chemiluminescence substrate (Thermo Fisher Scientific, Rockford, IL, USA) and visualized by film exposure. The density of the protein band was quantified using ImageJ software normalized by $\beta$-actin expression (Cell Signaling Technology, Danvers, MA, USA).

\subsubsection{Effect of HC Combined with Inhibitor on AP-A and Mineralization in Cells}

Cells $\left(5 \times 10^{3}\right.$ cells $/ 35 \mathrm{~mm}$ dish) were seeded into a 24 -well culture plate. Subsequently, the cells were treated with DM or DM containing HC at the selected concentration alone or pre-treated with $10 \mu \mathrm{M}$ Akt inhibitor (perifosine) for $1 \mathrm{~h}$ prior to the addition of DM containing $\mathrm{HC}$ at the selected concentration. After treatments, the cells were incubated for the selected time. At the end of culture period, the cells were determined for AP-A and mineralization using Alizarin red S staining as mentioned above.

\subsection{Statistical Analysis}

The experiments were run in triplicate and analysis of variance (ANOVA) was conducted for all the data. The Duncan's multiple range test was used for mean comparison. Statistical Package for Social Science (SPSS 11.0 for windows, SPSS Inc., Chicago, IL, USA) was used for data analysis. For Western blot analysis, the difference between samples was analyzed using a paired t-test.

\section{Results}

\subsection{Size Distribution of HC}

Several peaks of peptides having varying molecular weights (MWs) were observed in HC (Figure 1). Peptides with MWs of 888 and 1108 Da were dominant in HC. Moreover, peptides with low MW (<888 Da) and large MW ( $>1 \mathrm{kDa})$ were also detected. 


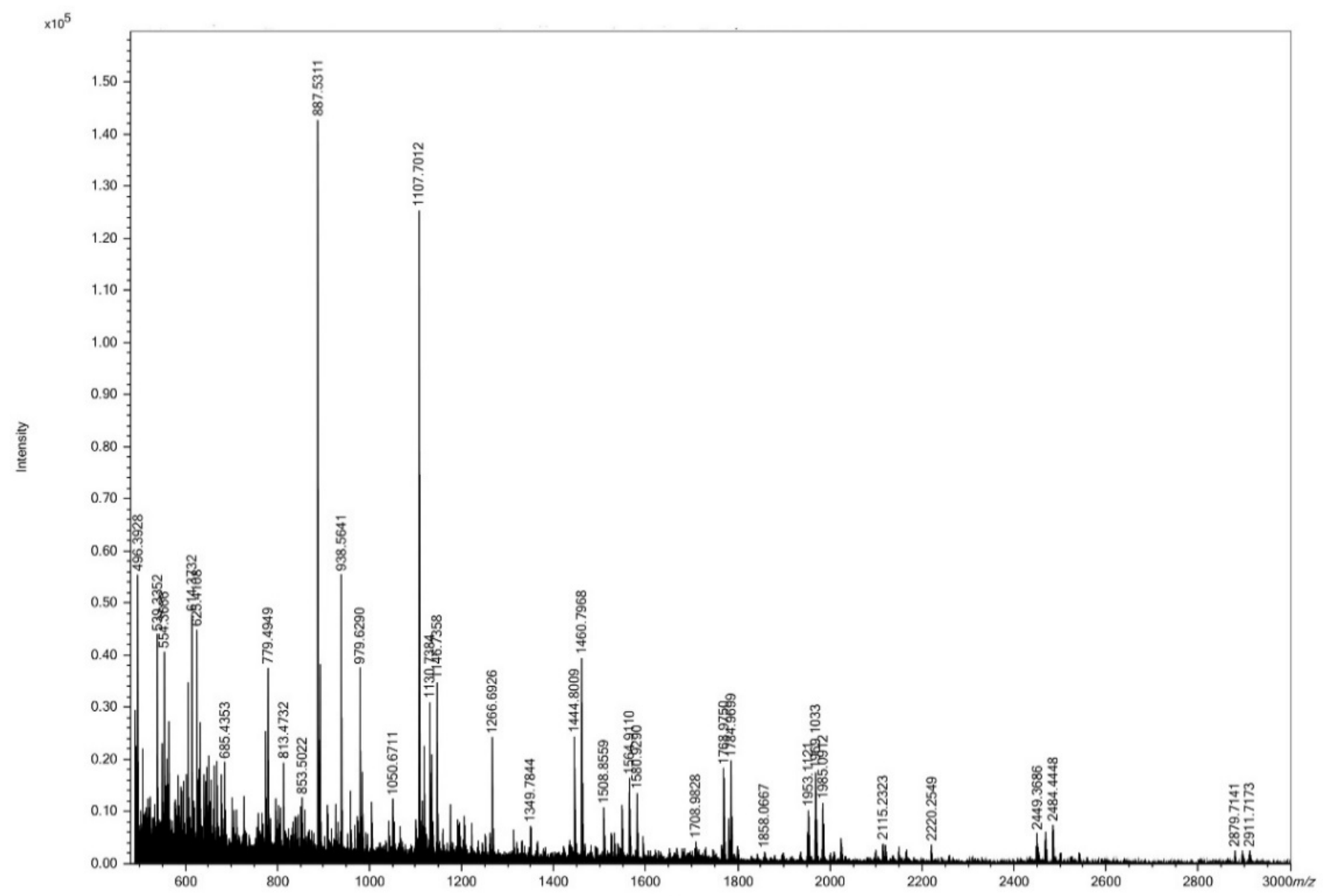

Figure 1. Size distribution of sea bass skin hydrolyzed collagen (HC) determined by MALDI-TOF mass spectrometry.

\subsection{Impact of HC on Proliferation, Alkaline Phosphatase Activity and Mineralization of MC3T3-E1 Cells}

\subsubsection{MC3T3-E1 Cell Proliferation}

The effect of HC on proliferation of MC3T3-E1 cells is depicted in Figure 2. In the presence of $10 \% \mathrm{FBS}, \mathrm{HC}$ at all concentrations $(50-800 \mu \mathrm{g} / \mathrm{mL})$ tested had no cytotoxicity on the MC3T3-E1 cells (Figure 2A). Moreover, cell viability was similar between the control (without HC) and those treated with HC at various concentrations $(p>0.05)$. This was ascertained by cell integrity of all samples (Figure 2C). When the level of FBS was reduced to $1 \%$, the proliferation of cells still increased with increasing concentrations of HC up to $200 \mu \mathrm{g} / \mathrm{mL}(p<0.05)$ (Figure 2B). Thus, $\mathrm{HC}$ at $200 \mu \mathrm{g} / \mathrm{mL}$ (or lower) was used for further studies. 
A

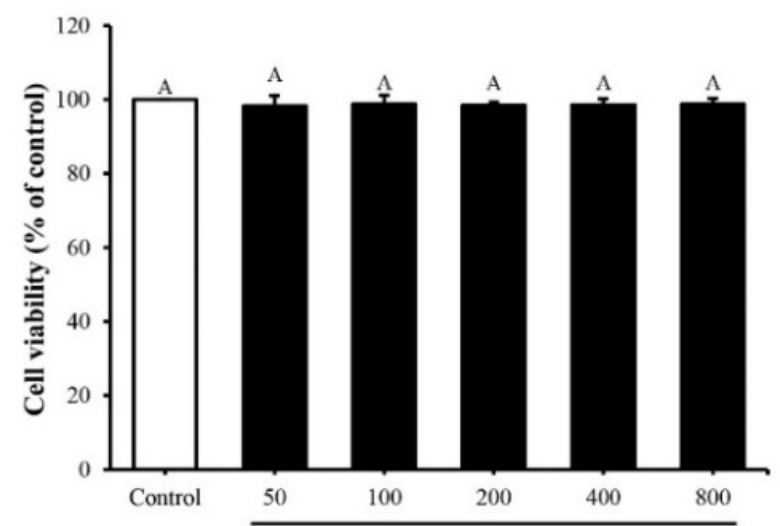

B

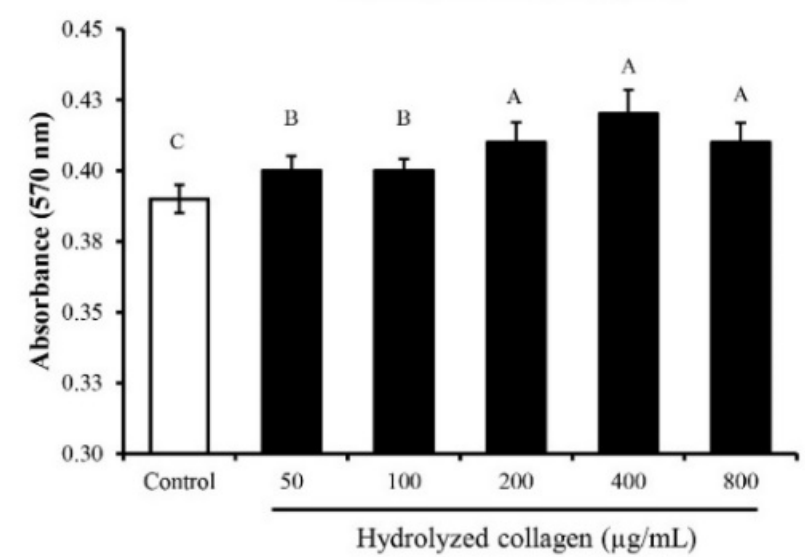

C

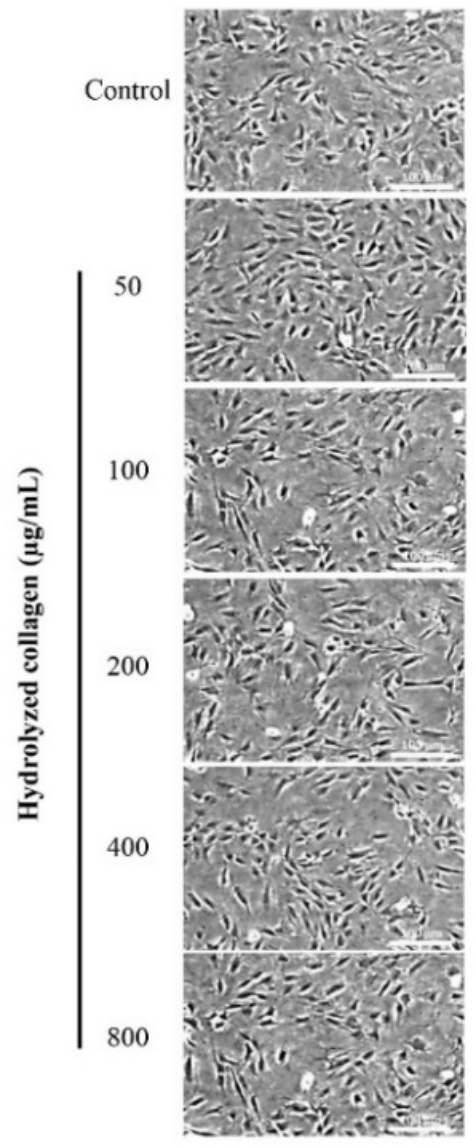

Figure 2. Effect of defatted sea bass skin hydrolyzed collagen (HC) dissolved in $\alpha$-MEM medium with $10 \%$ FBS (A) or $1 \%$ FBS (B) at various concentrations on proliferation of MC3T3-E1 pre-osteoblast cells. Cell morphology using scale bar of $100 \mu \mathrm{m}$ and magnification of $\times 10$ (C) after treatment with HC at various concentrations in the presence of $10 \%$ FBS. Incubation time of $24 \mathrm{~h}$ was used. Error bars represent standard deviation $(n=3)$. Different letters on bars indicate significant differences $(p<0.05)$.

\subsubsection{Alkaline Phosphatase Activity (AP-A)}

$\mathrm{HC}$ at all concentrations tested enhanced the differentiation of mesenchymal stem cells to osteoblast cells during the early stages, as evidenced by the increased AP-A with increasing incubation times $(p<0.05)$ (Figure 3A). When comparing AP-A between the samples at the same incubation time tested, there was no difference in AP-A of cells treated with $\mathrm{HC}$ at 50 and $200 \mu \mathrm{g} / \mathrm{mL}$ within the first 7 days of culture $(p>0.05)$, while $\mathrm{HC}$ at $100 \mu \mathrm{g} / \mathrm{mL}$ showed the highest AP-A $(p<0.05)$ (Figure 3A). Nevertheless, HC-treated cells had higher AP-A than the control (without HC) $(p<0.05)$. The results indicate that HC could induce differentiation of osteoblast cell as evidenced by the increased intensity of blue color (Figure 3B,C). After day 7 of culture, no difference in AP-A for all samples tested was found ( $p>0.05)$, except on the 14th day for cells treated with $200 \mu \mathrm{g} / \mathrm{mL} \mathrm{HC}$, which had the lowest AP-A (Figure 3A). 
A

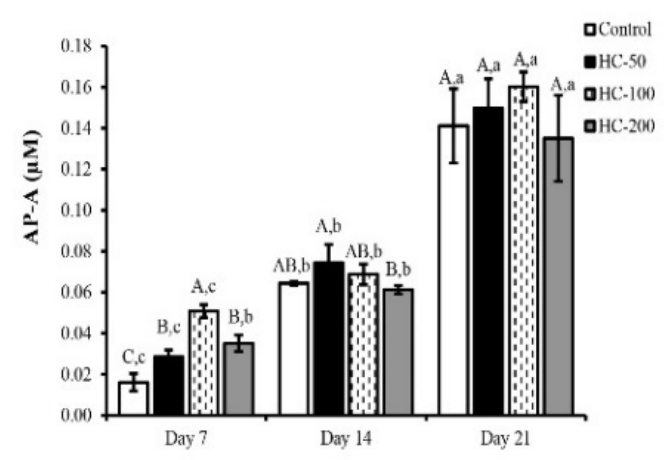

B

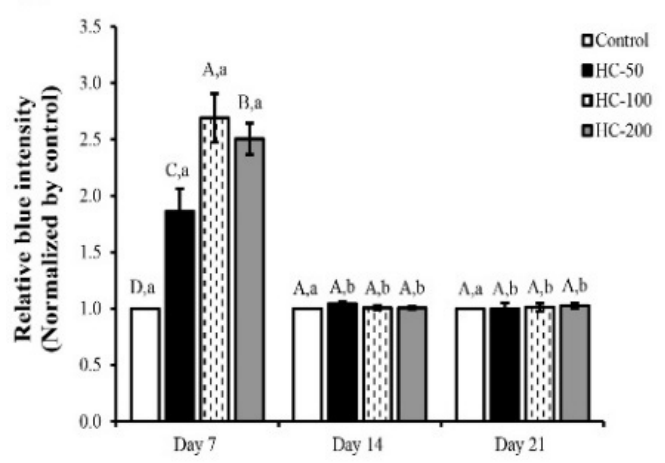

C

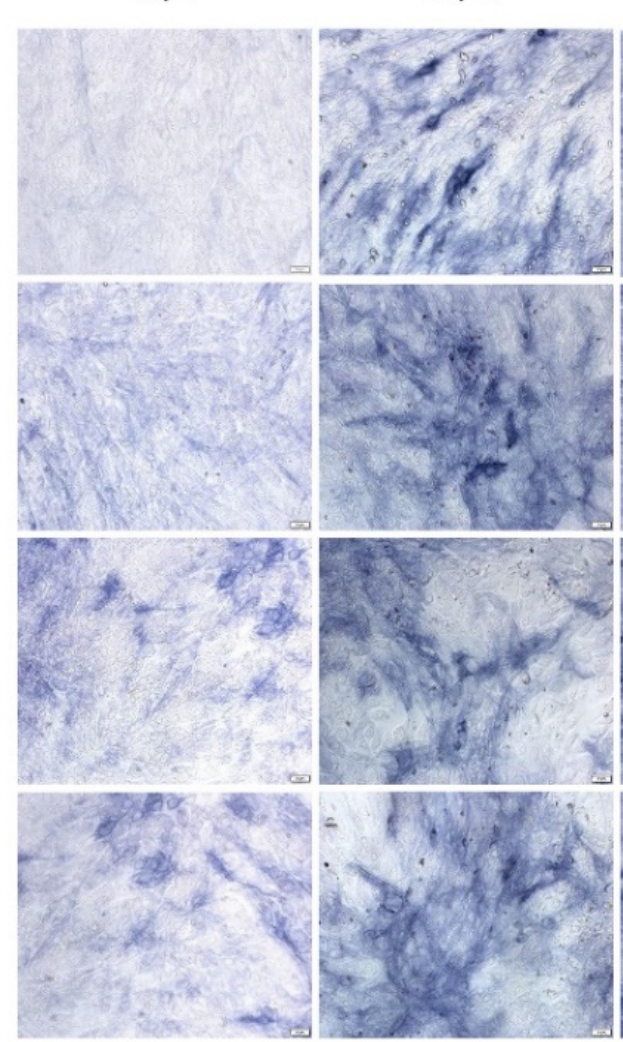

Day 21

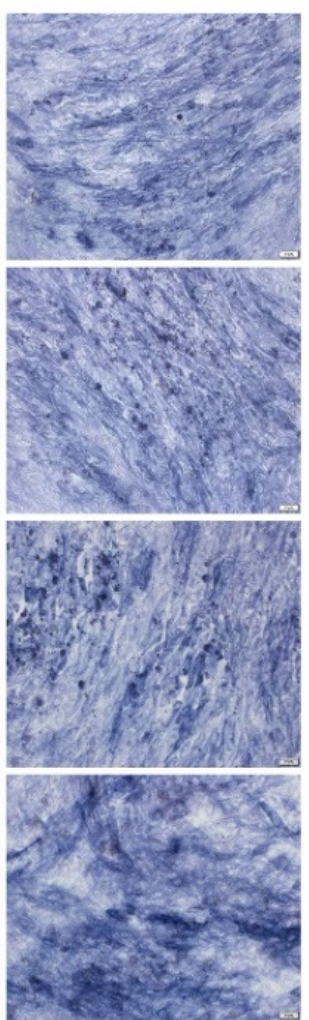

Control

HC-50

HC-100

Figure 3. Effect of defatted sea bass skin hydrolyzed collagen (HC) on (A) alkaline phosphatase activity (AP-A) of MC3T3E1 cells, $(\mathbf{B})$ relative blue intensity of alkaline phosphatase and (C) blue crystal staining intensity $(\mathrm{scale}$ bar $=100 \mu \mathrm{m}$; magnification $=\times 10$ ) at different culture times. Quantitative analysis of blue intensity was assessed using ImageJ software. Error bars represent standard deviation $(n=3)$. Different uppercase letters indicate significant differences between samples at the same culture time $(p<0.05)$. Different lowercase letters indicate significant differences between culture times of the same sample $(p<0.05)$.

\subsubsection{Mineralization of MC3T3-E1 Cells}

Mineralization of MC3T3-E1 cells was evaluated using calcium staining by Alizarin red S with the absorbance at $405 \mathrm{~nm}\left(\mathrm{~A}_{405}\right)$, as illustrated in (Figure 4). $\mathrm{HC}$ at all tested concentrations increased the cell mineralization as a function of time $(p<0.05)$, as indicated by the increased calcium deposition (red spot) (Figure 4A) and the augmented absorption at $405 \mathrm{~nm}$ (Figure 4B). On day 7, all samples tested had no difference in absorption intensity (Figure 4B) and the calcium deposition (Figure 4C) $(p>0.05)$. When the cell culture time was prolonged, higher absorption and increased calcium deposition were found for HCtreated cells than those of control, especially treatments with $\mathrm{HC}$ at 100 and $200 \mu \mathrm{g} / \mathrm{mL}$, which had the drastic increase in $\mathrm{A}_{405}(p<0.05)$. For calcium deposition, the highest nodule formation was observed when treated with $\mathrm{HC}$ at 100 and $200 \mu \mathrm{g} / \mathrm{mL}$, compared to the control (Figure 4A,C). However, on day 21, the same trend was found, but the relative deposition of calcium was lower when compared to day 14 (Figure 4C). 
$\mathbf{A}$

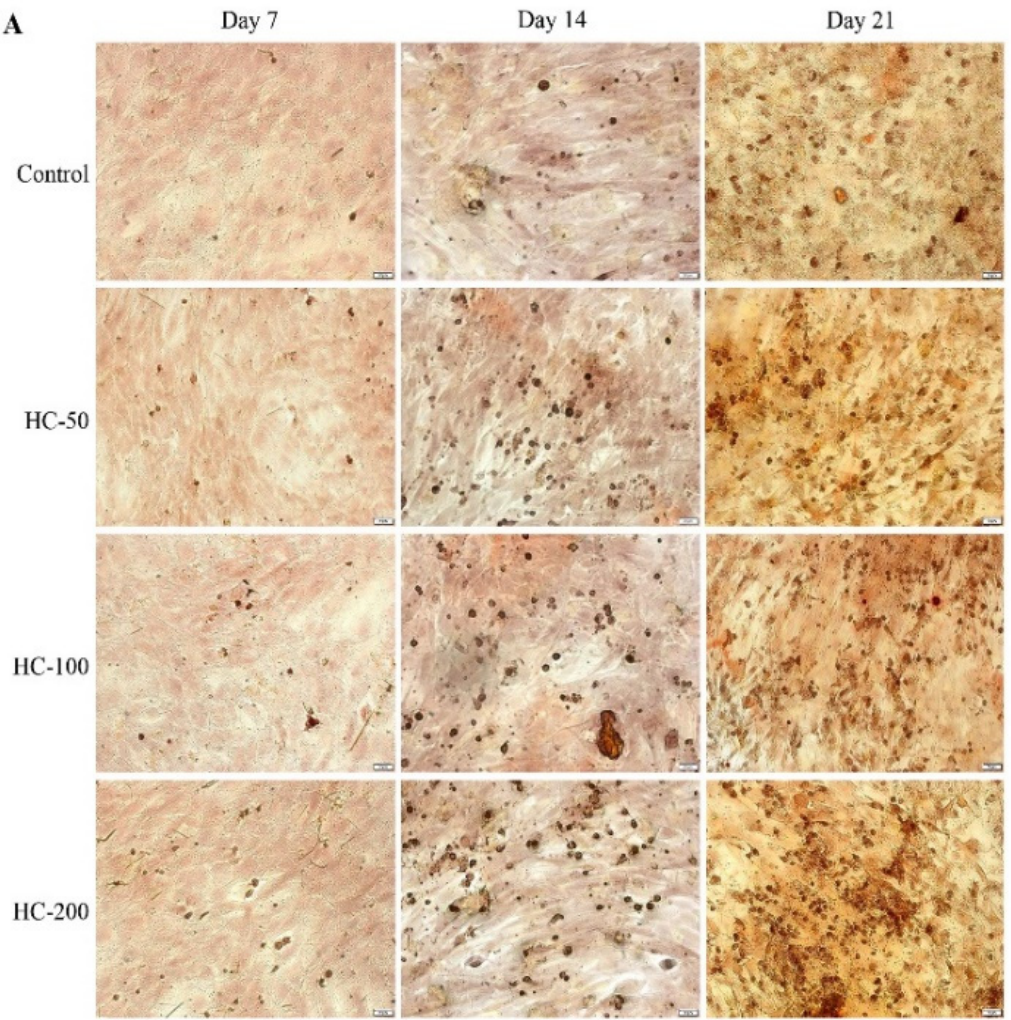

B

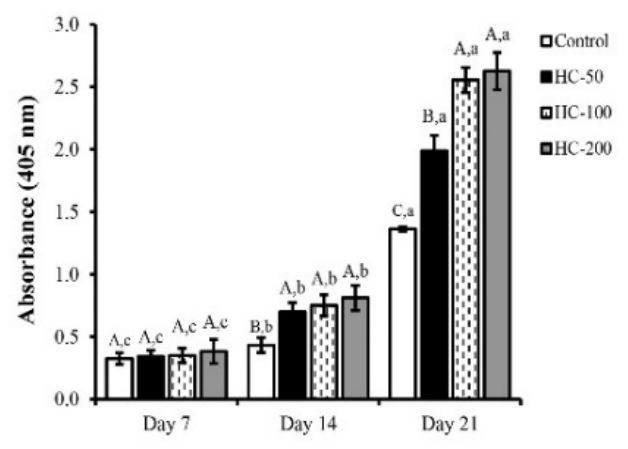

C

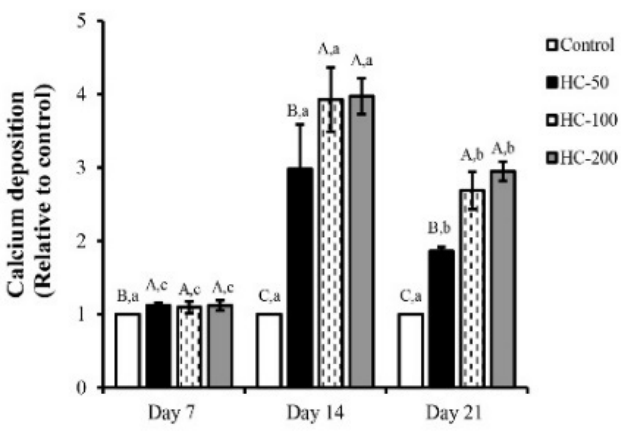

Figure 4. Effect of defatted sea bass skin hydrolyzed collagen (HC) on (A) mineralization of MC3T3-E1 cells (scale bar $=100 \mu \mathrm{m}$; magnification $=\times 10$ ) as indicated by $(\mathbf{B})$ changes in absorbance at $405 \mathrm{~nm}$ and $(\mathbf{C})$ calcium deposition during 21 days. Relative calcium deposition was assessed using ImageJ software. Error bars represent standard deviations $(n=3)$. Different uppercase letters indicate significant differences between samples at the same culture time $(p<0.05)$. Different lowercase letters indicate significant differences between culture times of the same sample $(p<0.05)$.

\subsection{Effect of HC on RUNX2 Expression in MC3T3-E1 Cells}

Based on the results shown in Figures 3 and 4, cell differentiation was obviously found during the first 14 days of the culture period. Additionally, there was no difference in cell differentiation between 100 and $200 \mu \mathrm{g} / \mathrm{mL} \mathrm{HC}$ treatments $(p>0.05)$. Thus, the cells treated with $100 \mu \mathrm{g} / \mathrm{mL} \mathrm{HC}$ for 7, 10 and 14 days were selected for measuring the protein levels of RUNX2 using Western blotting. Higher expression of RUNX2 was found in cells treated with HC when compared to the control $(p<0.05)$ for all culture times tested (Figure 5). Moreover, the expression level of RUNX2 in cell treated with HC increased up to the first 10 days of culture period $(p>0.05)$ (Figure 5A,B). Subsequently, the decrease in RUNX2 expression was found at day 14 of the culture period $(p<0.05)$ (Figure $5 \mathrm{~A}, \mathrm{~B})$. 
A

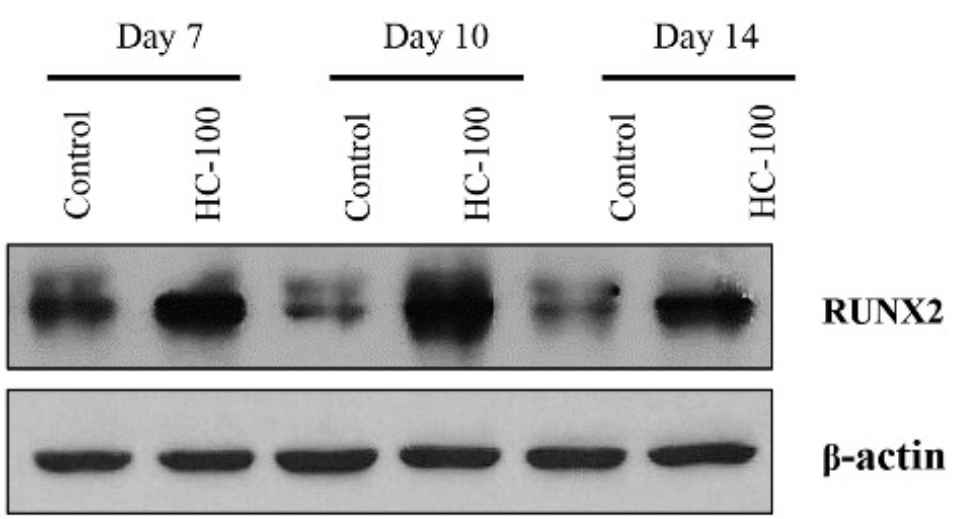

B

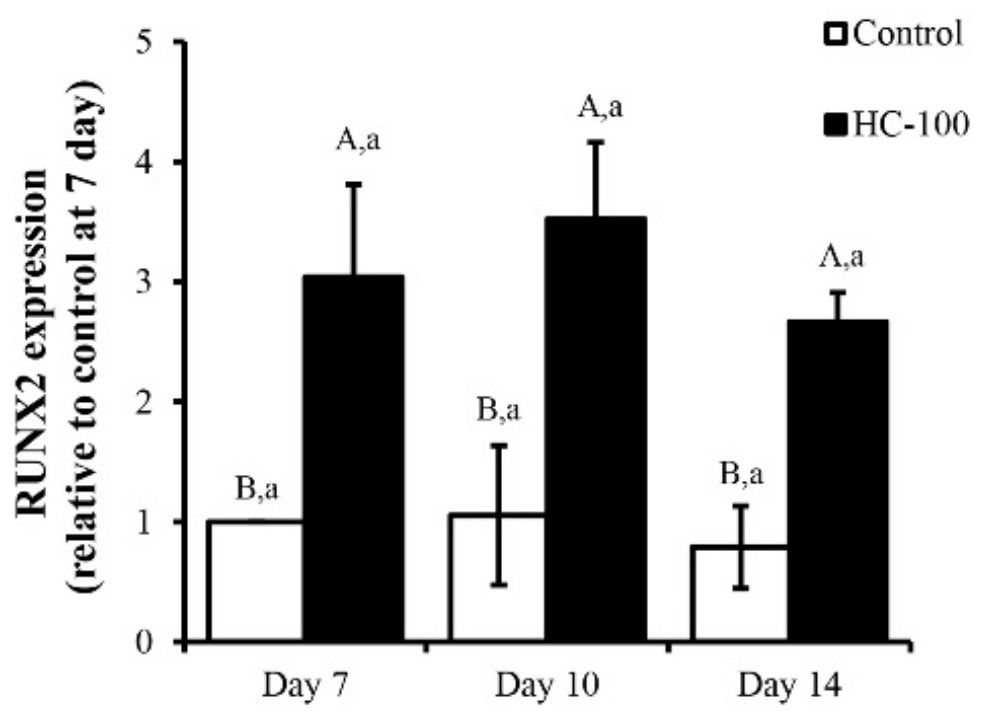

Figure 5. Effect of sea bass skin hydrolyzed collagen (HC) at $100 \mu \mathrm{g} / \mathrm{mL}$ on (A) expression level of RUNX2 in MC3T3-E1 cells after differentiation for 7, 10 and 14 days; (B) results are expressed as relative values to control at day 7. Error bars represent standard deviation $(n=3)$. Different uppercase letters indicate significant differences between samples at the same culture time $(p<0.05)$. Different lowercase letters indicate significant differences between culture times of the same sample $(p<0.05)$.

\subsection{Effect of HC on Akt Signaling Pathway in MC3T3-E1 Cells}

As presented in (Figure 6A,B), no difference in the expression level of Akt was found for the control at all times tested, while p-Akt was upregulated with increasing time (Figure 6A). To further investigate whether Akt signaling was related with HC in stimulation of the differentiation process of cells, the effect of $\mathrm{HC}$ incorporated with Akt inhibitor (perifosine) on AP-A (Figure 6C,D) and calcium deposition was examined (Figure 6E,F). The lowest AP-A was found for the untreated control cells $(p<0.05)$ (Figure 6C,D). In the presence of HC, AP-A was markedly increased $(p<0.05)$. When HC in combination with perifosine was used, AP-A level was decreased $(p<0.05)$, suggesting inhibition of the Akt signaling pathway. Additionally, there was no difference in absorption value for all samples tested within the first 7 days, regardless of inhibitor or HC addition $(p>0.05)$ (Figure 6F). The results suggest that calcium in cells was produced to a similar extent since cells were still in the early stage. 
A

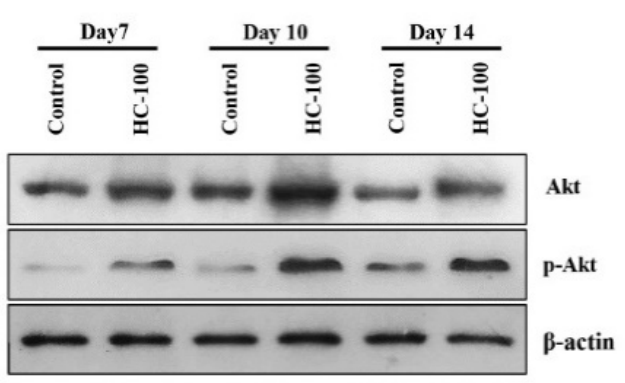

C

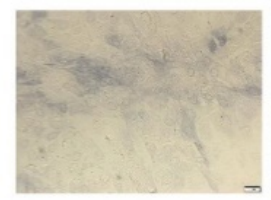

$\mathrm{HC}(100 \mu \mathrm{g} / \mathrm{mL})$ Perifosine $(10 \mu \mathrm{M})$

$\mathbf{E}$

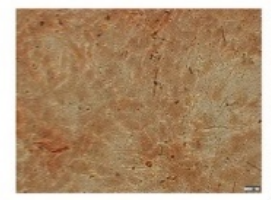

$\mathrm{HC}(100 \mu \mathrm{g} / \mathrm{mL})$ Perifosine $(10 \mu \mathrm{M})$
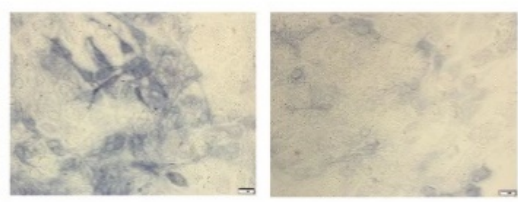

$+$

$-$

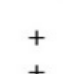

$+$ $\mathrm{HC}(100 \mu \mathrm{g} / \mathrm{mL})$
Perifosine $(10 \mu \mathrm{M})$

F
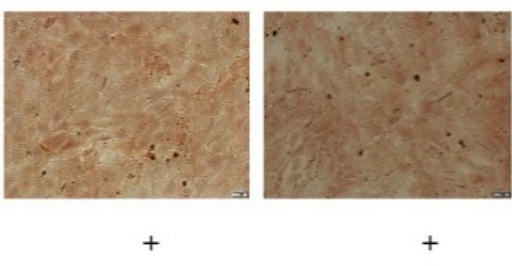

B

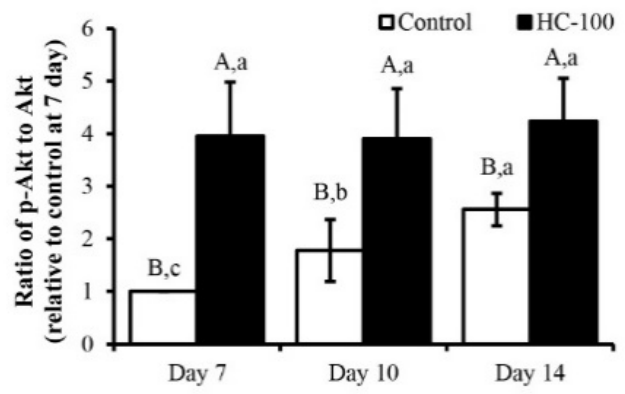

D
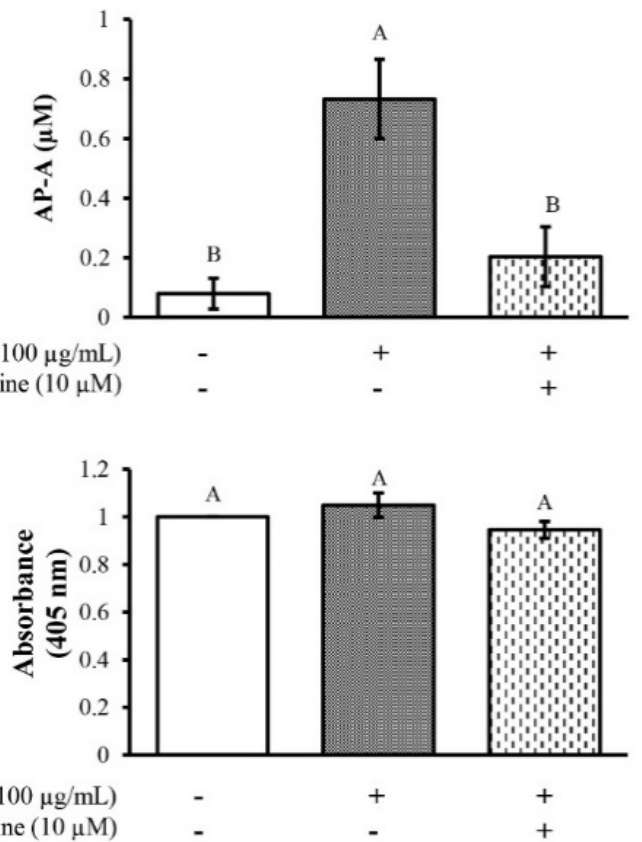

Figure 6. Effect of sea bass skin hydrolyzed collagen (HC) at $100 \mu \mathrm{g} / \mathrm{mL}$ on (A) expression of p-Akt, total Akt and $\beta$-actin protein expression of MC3T3-E1 cells after differentiation for 7, 10 and 14 days; (B) results are expressed as relative value to control at day 7; (C) images of blue crystal after staining with BCIP/NBT solution for $1 \mathrm{~h}$; (D) alkaline phosphatase activity (AP-A); (E) mineralization of cells; and (F) changes in absorbance at $405 \mathrm{~nm}$ after treatment with or without perifosine $(10 \mu \mathrm{M})$ for 7 days of differentiation. Error bars represent standard deviation $(n=3)$. Different uppercase letters indicate significant differences between samples at the same culture time $(p<0.05)$. Different lowercase letters indicate significant differences between culture times of the same sample $(p<0.05)$.

\section{Discussion}

The MWs of peptides in HC from the present study (Figure 1) were smaller than those of peptides from sea bass skin previously reported by Benjakul et al. [4,7]. In general, the size of peptides is a vital factor affecting bioactivity of HC [8]. Peptides of smaller sizes mostly exhibited higher bioactivities, especially osteoblast proliferation activity $[9,10]$. In addition, short chain peptides could be rapidly digested and absorbed in the human body [11]. The result implied that sea bass skin HC containing small peptides might have ability to proliferate osteoblast cells.

When HC was added into MC3T3-E1 osteoblast cells (Figure 2), it could promote proliferation and differentiation of MC3T3-E1 osteoblast cells, especially at the concentrations of HC up to $200 \mu \mathrm{g} / \mathrm{mL}$. The increased proliferation of cells indicated that HC could induce the proliferation of osteoblast cells. Peptides rich in hydrophobic AAs and imino acids might play a vital role in proliferation $[9,12]$. Moreover, HC rich in Pro-Hyp and Pro-Hyp-Gly have been shown to induce the growth of osteoblast cells [12,13], and a previous work has demonstrated the presence of these peptides in HC from sea bass skin [14]. Apart from peptides containing Pro-Hyp and Pro-Hyp-Gly, low molecular weight peptides $(<1 \mathrm{kDa})$ had the ability to enhance osteoblast proliferation $[9,15]$. Our previous 
work showed the presence of low MW peptides (<750 Da) in defatted sea bass skin HC [7], which may have contributed to stimulation of osteoblast proliferation.

When MC3T3-E1 cells were used to determine the impact of HC on cell differentiation, HC could induce differentiation of osteoblast cells, as witnessed by the increased AP-A (Figure 3A). In general, AP is a marker of bone formation and differentiation of osteoblasts [16], which hydrolyzes pyrophosphate and provides inorganic phosphate to promote mineralization in osteoblasts [16]. Thus, the addition of HC peptides with high imino acids or hydrophobic AAs, particularly at the level of $100 \mu \mathrm{g} / \mathrm{mL}$, more likely promoted differentiation of bone cells during the first 7 days of the culture period. Nevertheless, no change in AP-A was observed after 7 day of culture. This phenomenon might be due to the different stages of cell differentiation. This result was confirmed by differences in the intensity of the blue color on day 14 and day 21 (Figure 3B,C).

Apart from AP-A, HC could also stimulate mineralization of osteoblast cells (Figure 4), which was consistent with the AP-A results (Figure 3). Changes in the differentiation process of osteoblast cells plausibly occurred from the early stage to final stage after 7 days of culture, leading to the increased mineralized nodule formation, as indicated by the augmented absorption (Figure 4B) and enhanced calcium deposition (Figure 4C). The mineralization process is commonly the final step of osteogenic differentiation [17]. During this process, calcium phosphate nanocrystals are produced by osteoblast cells, which are aligned in the collagen based fibrous matrix [18]. The addition of HC from defatted sea bass skin might aid the promotion of cell matrix mineralization, thus leading to enhanced mineralized nodule formation.

When MC3T3-E1 cells were used to examine the effect of HC on the regulation of RUNX2 genes associated with osteoblast differentiation during the early phase, cells treated with HC showed higher expression of RUNX2 than the control $(p<0.05)$ for all culture times tested (Figure 5), indicating accelerated differentiation of MC3T3-E1 cells by the collagen peptides. However, the decrease in RUNX2 expression after 10 days of the culture period (Figure 5A,B) indicated the change in differentiation phase of cells from early phase to last phase, as shown by the increased calcium deposition of the cells (Figure 4C).

Furthermore, Akt signaling, which is a key pathway regulating several processes, including proliferation, differentiation and survival of cells, was investigated [19]. The upregulation of p-Akt with increasing time was obtained (Figure 6A), indicating that differentiation of cells occurred. This might be due to phosphorylation of Akt at Ser473, thus sustaining the phosphorylated/activated levels [20]. Activated Akt commonly stimulates its downstream signaling cascades to promote transcriptional and translational activities of targeted proteins, namely, RUNX2, Osterix [21]. During bone differentiation, activated Akt is required to enhance RUNX2 transcription, increase AP-A and promote bone mineralization [22,23].

Additionally, the incorporation of $\mathrm{HC}$ with perifosine (Akt inhibitor) revealed that $\mathrm{HC}$ could stimulate cell differentiation in the early stage via the Akt pathway as indicated by the decreased AP levels when perifosine was added (Figure 6C,D). Thus, cell mineralization could not occur, as ascertained by the fewer mineralized nodules with the presence of perifosine (Figure 6E,F).

\section{Conclusions}

HC from defatted sea bass skin had peptides with MW $<3 \mathrm{kDa}$. HC stimulated growth and differentiation of osteogenic MC3T3-E1 cells in the first stage and resulted in acceleration of calcium deposition in the last stage. Addition of $\mathrm{HC}$ to the cells led to increased expression of RUNX2 proteins coupled with enhanced calcium deposition, which were attributed to activation of the Akt signaling pathway. Therefore, HC from fish skin can serve as a functional ingredient and nutraceutical for bone strengthening, in which potential alleviation of osteoporosis and related diseases can be achieved. Nevertheless, the efficiency of $\mathrm{HC}$ on prevention of osteoporosis needs to be further investigated using bone resorption and osteoclast differentiation both in in vitro and in vivo models. 
Author Contributions: L.C. and T.B.: conceptualization, investigation of the experiments and writing of the original draft. P.H., S.T. and B.Z.: reviewed the manuscript. R.E.A. and S.B.: conceptualization, supervision and editing of the manuscript. All authors have read and agreed to the published version of the manuscript.

Funding: This research was supported by the National Research Council of Thailand (NRCT) under the International Research Network (IRN) program and National Science and Technology Development Agency (Grant No. P-20-52297). Financial support was provided by Prince of Songkla University under the Prachayacharn grant (AGR6402088N).

Institutional Review Board Statement: Not applicable.

Informed Consent Statement: Not applicable.

Data Availability Statement: The data are not shared.

Conflicts of Interest: There are no conflict of interest.

\section{References}

1. Chotphruethipong, L.; Aluko, R.E.; Benjakul, S. Hydrolyzed collagen from porcine lipase-defatted seabass skin: Antioxidant, fibroblast cell proliferation, and collagen production activities. J. Food Biochem. 2019, 43, 1-13. [CrossRef] [PubMed]

2. Chotphruethipong, L.; Aluko, R.E.; Benjakul, S. Effect of pulsed electric field-assisted process in combination with porcine lipase on defatting of seabass skin. J. Food Sci. 2019, 84, 1799-1805. [CrossRef]

3. Chotphruethipong, L.; Aluko, R.E.; Benjakul, S. Enhanced Asian sea bass skin defatting using porcine lipase with the aid of pulsed electric field pretreatment and vacuum impregnation. Process Biochem. 2019, 86, 58-64. [CrossRef]

4. Benjakul, S.; Karnjanapratum, S.; Visessanguan, W. Hydrolysed collagen from Lates calcarifer skin: Its acute toxicity and impact on cell proliferation and collagen production of fibroblasts. Int. J. Food Sci. Technol. 2018, 53, 1871-1879. [CrossRef]

5. Paisrisarn, P.; Tepaamorndech, S.; Khongkow, M.; Khemthong, P.; Kasamechonchung, P.; Klysubun, W.; Wutikhun, T.; Huang, L.; Chantarasakha, K.; Boonrungsiman, S. Alterations of mineralized matrix by lead exposure in osteoblast (MC3T3-E1) culture. Toxicol. Lett. 2018, 299, 172-181. [CrossRef] [PubMed]

6. Li, Y.; Kim, J.H.; Choi, E.H.; Han, I. Promotion of osteogenic differentiation by non-thermal biocompatible plasma treated chitosan scaffold. Sci. Rep. 2019, 9, 3712. [CrossRef] [PubMed]

7. Chotphruethipong, L.; Sukketsiri, W.; Aluko, R.E.; Sae-leaw, T.; Benjakul, S. Effect of hydrolyzed collagen from defatted Asian sea bass (Lates calcarifer) skin on fibroblast proliferation, migration and antioxidant activities. J. Food Sci. Technol. 2020, 58, 541-551. [CrossRef] [PubMed]

8. Tao, J.; Zhao, Y.-Q.; Chi, C.-F.; Wang, B. Bioactive peptides from cartilage protein hydrolysate of spotless smoothhound and their antioxidant activity in vitro. Mar. Drugs 2018, 16, 100. [CrossRef]

9. Wang, J.; Zhang, B.; Lu, W.; Liu, J.; Zhang, W.; Wang, Y.; Ma, M.; Cao, X.; Guo, Y. Cell proliferation stimulation ability and osteogenic activity of low molecular weight peptides derived from bovine gelatin hydrolysates. J. Agric. Food Chem. 2020, 68, 7630-7640. [CrossRef]

10. Ye, M.; Jia, W.; Zhang, C.; Shen, Q.; Zhu, L.; Wang, L. Preparation, identification and molecular docking study of novel osteoblast proliferation-promoting peptides from yak (Bos grunniens) bones. RSC Adv. 2019, 9, 14627-14637. [CrossRef]

11. Karami, Z.; Akbari-Adergani, B. Bioactive food derived peptides: A review on correlation between structure of bioactive peptides and their functional properties. J. Food Sci. Technol. 2019, 56, 535-547. [CrossRef] [PubMed]

12. Kimira, Y.; Ogura, K.; Taniuchi, Y.; Kataoka, A.; Inoue, N.; Sugihara, F.; Nakatani, S.; Shimizu, J.; Wada, M.; Mano, H. Collagenderived dipeptide prolyl-hydroxyproline promotes differentiation of MC3T3-E1 osteoblastic cells. Biochem. Biophys. Res. Commun. 2014, 453, 498-501. [CrossRef] [PubMed]

13. Kimira, Y.; Odaira, H.; Nomura, K.; Taniuchi, Y.; Inoue, N.; Nakatani, S.; Shimizu, J.; Wada, M.; Mano, H. Collagen-derived dipeptide prolyl-hydroxyproline promotes osteogenic differentiation through Foxg1. Cell. Mol. Biol. Lett. 2017, 22, 27. [CrossRef] [PubMed]

14. Sae-leaw, T.; Karnjanapratum, S.; O'Callaghan, Y.C.; O'Keeffe, M.B.; FitzGerald, R.J.; O'Brien, N.M.; Benjakul, S. Purification and identification of antioxidant peptides from gelatin hydrolysate of seabass skin. J. Food Biochem. 2017, 41, 1-11. [CrossRef]

15. Heo, S.-Y.; Ko, S.-C.; Nam, S.Y.; Oh, J.; Kim, Y.-M.; Kim, J.-I.; Kim, N.; Yi, M.; Jung, W.-K. Fish bone peptide promotes osteogenic differentiation of MC3T3-E1 pre-osteoblasts through upregulation of MAPKs and Smad pathways activated BMP-2 receptor. Cell Biochem. Funct. 2018, 36, 137-146. [CrossRef]

16. Wang, J.; Liu, J.; Guo, Y. Cell Growth Stimulation, Cell Cycle Alternation, and Anti-Apoptosis Effects of Bovine Bone Collagen Hydrolysates Derived Peptides on MC3T3-E1 Cells Ex Vivo. Molecules 2020, 25, 2305. [CrossRef]

17. Wu, W.; He, L.; Li, C.; Zhao, S.; Liang, Y.; Yang, F.; Zhang, M.; Jin, G.; Ma, M. Phosphorylation of porcine bone collagen peptide to improve its calcium chelating capacity and its effect on promoting the proliferation, differentiation and mineralization of osteoblastic MC3T3-E1 cells. J. Funct. Foods 2020, 64, 103701. [CrossRef] 
18. Blair, H.C.; Larrouture, Q.C.; Li, Y.; Lin, H.; Beer-Stoltz, D.; Liu, L.; Tuan, R.S.; Robinson, L.J.; Schlesinger, P.H.; Nelson, D.J. Osteoblast differentiation and bone matrix formation in vivo and in vitro. Tissue Eng. Part B Rev. 2017, 23, 268-280. [CrossRef]

19. Gu, Y.X.; Du, J.; Si, M.S.; Mo, J.J.; Qiao, S.C.; Lai, H.C. The roles of PI3K/Akt signaling pathway in regulating MC3T3-E1 preosteoblast proliferation and differentiation on SLA and SLActive titanium surfaces. J. Biomed. Mater. Res. Part A 2013, 101, 748-754. [CrossRef]

20. Chu, N.; Salguero, A.L.; Liu, A.Z.; Chen, Z.; Dempsey, D.R.; Ficarro, S.B.; Alexander, W.M.; Marto, J.A.; Li, Y.; Amzel, L.M.; et al. Akt kinase activation mechanisms revealed using protein semisynthesis. Cell 2018, 174, 897-907.e14. [CrossRef]

21. Gomathi, K.; Akshaya, N.; Srinaath, N.; Moorthi, A.; Selvamurugan, N. Regulation of Runx2 by post-translational modifications in osteoblast differentiation. Life Sci. 2020, 245, 117389. [CrossRef] [PubMed]

22. Cohen-Solal, K.A.; Boregowda, R.K.; Lasfar, A. RUNX2 and the PI3K/AKT axis reciprocal activation as a driving force for tumor progression. Mol. Cancer 2015, 14, 137. [CrossRef] [PubMed]

23. Wu, C.-M.; Chen, P.-C.; Li, T.-M.; Fong, Y.-C.; Tang, C.-H. Si-Wu-tang extract stimulates bone formation through PI3K/Akt/NF- $\mathrm{kB}$ signaling pathways in osteoblasts. BMC Complement. Altern. Med. 2013, 13, 277. [CrossRef] [PubMed] 